\title{
SPHAERIDIOTREMA GLOBULUS AND SPHAERIDIOTREMA PSEUDOGLOBULUS (DIGENEA): SPECIES DIFFERENTIATION BASED ON mIDNA (BARCODE) AND PARTIAL LSU-rDNA SEQUENCES
}

\author{
Laura Bergmame, Jane Huffman*, Rebecca Cole †, Selvadurai Dayanandan, Vasyl Tkach $\neq$, and J. Daniel McLaughlin \\ Department of Biology, Concordia University, Montreal, Quebec, Canada H4B 1R6. e-mail: mcljd@alcor.concordia.ca
}

\begin{abstract}
Flukes belonging to Sphaeridiotrema are important parasites of waterfowl, and 2 morphologically similar species Sphaeridiotrema globulus and Sphaeridiotrema pseudoglobulus, have been implicated in waterfowl mortality in North America. Cytochrome oxidase I (barcode region) and partial LSU-rDNA sequences from specimens of $S$. globulus and S. pseudoglobulus, obtained from naturally and experimentally infected hosts from New Jersey and Quebec, respectively, confirmed that these species were distinct. Barcode sequences of the 2 species differed at 92 of 590 nucleotide positions $(15.6 \%)$ and the translated sequences differed by 13 amino acid residues. Partial LSU-rDNA sequences differed at 29 of 1,208 nucleotide positions (2.4\%). Additional barcode sequences from specimens collected from waterfowl in Wisconsin and Minnesota and morphometric data obtained from specimens acquired along the north shore of Lake Superior revealed the presence of $S$. pseudoglobulus in these areas. Although morphometric data suggested the presence of $S$. globulus in the Lake Superior sample, it was not found among the specimens sequenced from Wisconsin or Minnesota.
\end{abstract}

Trematodes belonging to Sphaeridiotrema Odhner, 1913 are important parasites of waterfowl. Historically, specimens found in waterfowl in eastern North American have been identified as a single species, Sphaeridiotrema globulus (Rudolphi, 1814) (see Price, 1934; Gower, 1938; Cornwell and Cowan, 1963; Trainer and Fischer, 1963; Speckmann et al., 1972; Roscoe and Huffman, 1982, 1983; Hoeve and Scott, 1988; Huffman and Roscoe, 1989; Sauer et al., 2007). In most cases, reports of the parasite are accompanied by reports of hemorrhagic enteritis and mortality. Exceptions to this include studies by Gower (1938) and Hoeve and Scott (1988). Thus, Gower (1938) found no effects of $S$. globulus in lightly infected goldeneyes (presumably Bucephala clangula) or in lesser scaup (Aythya affinis) infected by "literally hundreds" of flukes in Michigan. Hoeve and Scott (1988) found mean intensities ranging from 4,699 to 12,419 flukes in bluewinged teal (Anas discors), black ducks (Anas rubripes), and mallards (Anas platyrhynchos) found dead in Quebec in 1984 and 1985 , but there was no report of hemorrhagic enteritis in these birds or in blue-winged teal that acquired 4-2,757 flukes when exposed for $24 \mathrm{hr}$ in sentinel cages. Similar pathological inconsistencies have been reported elsewhere (see McLaughlin et al., 1993; Huffman, 2008), suggesting the possibility that other species may have been mistakenly identified as $S$. globulus.

The pathological effects of $S$. globulus in naturally and experimentally infected waterfowl in New Jersey have been well described with hemorrhagic enteritis and mortality being the common endpoints (Roscoe and Huffman, 1983, 1984; Huffman and Roscoe, 1989; Mucha and Huffman, 1991). However, neither blue-winged teal nor domestic ducklings experimentally infected with metacercariae from Bithynia tentaculata in Quebec, Canada, displayed the symptoms or mortality characteristic of $S$. globulus reported in New Jersey (Gagnon, 1990). Subsequent morphological study of adult flukes from ducks experimentally infected with metacercariae from New Jersey and Quebec revealed that the specimens were different species (McLaughlin et al., 1993). Specimens

Received 30 October 2009; revised 6 June 2011; accepted 13 June 2011. * Department of Biological Sciences, East Stroudsburg University, East Stroudsburg, Pennsylvania 18301.

$\dagger$ United States Geological Survey, National Wildlife Health Center, 6006 Schroeder Road, Madison, Wisconsin 53711.

\$Department of Biology, University of North Dakota, Grand Forks, North Dakota 58202.

DOI: $10.1645 / G E-2370.1$ from New Jersey, which cause severe and frequently fatal hemorrhagic enteritis in waterfowl, were similar to the type specimens of $S$. globulus and were referred to that species. The specimens from Quebec were designated as a new species, Sphaeridiotrema pseudoglobulus McLaughlin, Scott and Huffman, 1993. These flukes do not cause the acute hemorrhagic enteritis in experimentally infected ducks, but nonetheless may be pathogenic to waterfowl when present in large numbers (Hoeve and Scott, 1988).

Morphologically, S. globulus and S. pseudoglobulus are readily identifiable at the generic level, but are difficult to distinguish at the species level. These difficulties are exacerbated by specimen deterioration caused by delays in necropsy common in hosts examined during die-offs, and by freezing of the carcass. In view of the difficulties encountered in identifying such specimens, alternative methods for resolving species within Sphaeridiotrema are required.

Ribosomal DNA sequences provide an alternative to morphologically based taxonomic methods within the platyhelminthes and, more specifically, the digenea (Nolan and Cribb, 2005; Olson and Tkach, 2005). They are particularly useful when specimens are unsuitable for morphological assessment. Mitochondrial gene sequences are less commonly used (Olson and Tkach, 2005). However, recent work by Moszczynska et al. (2009), Locke, McLaughlin, and Marcogliese (2010), Locke, McLaughlin, Dayanandan, and Marcogliese (2010), and Locke et al. (2011) has shown that DNA barcode sequences are also an effective means of distinguishing species within an array of digenean genera. The DNA barcode region near the $5^{\prime}$ end of the cytochrome c oxidase gene has been used as a marker for species identification across a wide range of animal taxa (e.g., Hebert et al., 2003; Cywinska et al., 2006; Hajibabaei et al., 2006). The LSU region is the largest of the conserved regions in the rDNA gene. Although used primarily in investigations of higher-level phylogenies, it has also been used successfully for species-level discrimination of species within the digenea (see Olson and Tkach, 2005). In the present study, we assess the effectiveness of DNA barcode sequences and partial sequences of the large subunit region of ribosomal DNA (LSUrDNA) as a means of distinguishing between these species.

\section{MATERIALS AND METHODS}

The specimens examined were obtained from naturally and experimentally infected waterfowl and from naturally infected snails collected from 
various localities over a period of several years. Sphaeridiotrema globulus were obtained from domestic ducks experimentally infected with metacercariae from Elimia virginica (Lake Musconetcong, New Jersey [McLaughlin et al., 1993]), from infected mute swans (Cygnus olor) (Lake Musconetcong), and from $C$. olor and $E$. virginica from Furnace Lake, New Jersey. Additional samples of adult flukes, provisionally identified as $S$. globulus, were obtained from lesser scaup (Aythya affinis) found dead at the South Shore Yacht Club in Port Washington near Milwaukee, Wisconsin in 2002 and on Lake Winnibigoshish, Minnesota in 2008. Larval stages were obtained from B. tentaculata from Lake Onalaska, Wisconsin in 2007. Specimens of $S$. pseudoglobulus were obtained from domestic ducks experimentally infected with metacercariae from B. tentaculata from Rivière du Sud, Quebec, Canada (McLaughlin et al., 1993), from 2 greater scaup (Aythya marilis) found dead on Lake St. Louis, which borders the Island of Montreal, Canada, in 2007 and 2008, and from B. tentaculata collected from Lac St. Louis in 2007. The flukes retained from the study by McLaughlin et al. (1993) had been frozen at $-80 \mathrm{C}$ in a small drop of water. The remaining adult specimens were taken from waterfowl that were found dead and had been frozen until they were examined. Samples from these birds and samples of larval stages from freshly killed snails were preserved in either $95 \%$ ethanol or absolute ethanol.

We also examined specimens of formalin-fixed flukes identified as $S$. globulus collected from 10 greater scaup found dead on the north shore of Lake Superior near Black Bay, Ontario, Canada, in the spring of 1990. These were stained in acetocarmine, dehydrated, cleared, and mounted in Canada balsam, and the largest mature egg in each specimen was measured. Sphaeridiotrema globulus has smaller eggs than S. pseudoglobulus (although the upper range of the former overlaps slightly with the lower range of the latter) and measurements were taken as a means of potentially distinguishing the species should the molecular evidence support previous morphometric work (McLaughlin et al., 1993).

DNA was extracted from individual flukes, rediae, and cercariae with the use of DNeasy ${ }^{\mathrm{TM}}$ tissue extraction kits (Qiagen, Valencia, California) in accordance with the manufacturer's protocols. PCR reactions had a total volume of $25 \mu \mathrm{l}$ that included $17.5 \mu \mathrm{l}$ ultrapure water, $2.5 \mu 110 x$ PCR buffer, $1.25 \mu \mathrm{l} 50 \mathrm{mM} \mathrm{MgCl}_{2}$ (both provided with the Taq), $0.125 \mu \mathrm{l}$ $10 \mathrm{mM}$ dNTP, $1.25 \mu 110 \mathrm{pmol}$ of each primer, $0.125 \mu \mathrm{l}$ Platinum Taq Polymerase (Invitrogen, Carlsbad, California), and $3 \mu \mathrm{l}$ of template.

The COI primers used were MplatCoxldF and MplatCOX1dR developed by Moszczynska et al. (2009). These primers include M13 tails (M13 [-21]F) and M13 ([-27]R) at the 5' ends. The original cycling parameters reported in Moszczynska et al. (2009) have been modified as follows: $94 \mathrm{C} / 1 \mathrm{~min}, 5$ cycles ( $94 \mathrm{C} / 40 \mathrm{sec}, 45 \mathrm{C} / 40 \mathrm{sec}, 72 \mathrm{C} / 1 \mathrm{~min}$ ) followed by 35 cycles $(94 \mathrm{C} / 40 \mathrm{sec}$, $51 \mathrm{C} / 40 \mathrm{sec}, 72 \mathrm{C} / 1 \mathrm{~min}$ ) with a final extension at $72 \mathrm{C}$ for $1 \mathrm{~min}$. These primers were also used for sequencing.

A region at the $5^{\prime}$ end of the $28 \mathrm{~S}$ ribosomal DNA gene including variable domains D1-D3 was amplified by PCR according to the protocol described by Tkach et al. (2003). Forward primer digl2 (5'-AAGCATATCACTAAGCGG-3') and reverse primer 1500R (5'- GCTATCCTGAGGGAAACTTCG $-3^{\prime}$ ) were used for amplification. PCR primers as well as several internal primers were used in sequencing reactions. These included internal forward primers: 300F (5'-CAAGTACCGTGAGGGAAAGTTG-3'), 900F (5'-CCGTCTTGAAACACGGACCAAG-3') and internal reverse primers: 300R (5'-CAACTTTCCCTCACGGTACTTG-3'), ECD2 (5'CTTGGTCCGTGTTTCAAGACGGG-3').

PCR products were visualized under UV light on $1 \%$ agarose gels containing ethidium bromide, purified using Qiagen Qiaquick ${ }^{\mathrm{TM}}$ columns, and cycle-sequenced directly using ABI BigDye ${ }^{\mathrm{TM}}$ (Foster City, California) chemistry. Sequencing of approximately half of the barcode and LSU samples was done at the Genome Quebec Centre, McGill University, Montreal, Quebec, Canada. The remaining barcode samples were sequenced at the Canadian Centre for DNA Barcoding at the University of Guelph, Guelph, Ontario, Canada; the remaining LSU samples were sequenced at the University of North Dakota. Nucleotide and amino acid sequences (translated with the use of trematode mitochondrial codons) were assembled, edited, and aligned with the use of Invitrogen Vector 10 and Sequencher ${ }^{\mathrm{TM}}$ (GeneCodes Corp., ver. 4.1.4) software. We took a conservative approach to sequence analysis by using only data from the regions covered by the forward and reverse strands. Barcode sequences and partial LSU-rDNA sequences have been deposited in Genbank under accession numbers GQ890328-GQ890331. Additional barcode sequences and their trace files are available in project SPHAE at www.barcodinglife. org.

\section{RESULTS}

Identification of the Quebec and New Jersey samples was based on specimens from the populations from experimentally infected hosts obtained during morphological studies on $S$. globulus and $S$. pseudoglobulus (McLaughlin et al., 1993).

We obtained 65 partial barcode sequences from Quebec $(N=21)$, Wisconsin/Minnesota $(N=19)$ and New Jersey $(N=25)$ and 14 partial LSU sequences; Quebec $(N=5)$, Wisconsin/Minnesota $(N=5)$ and New Jersey $(N=4)$. The majority of the barcode sequences were from adult flukes, but several sequences in each group were from larval stages. All of the LSU sequences were from adult specimens.

All specimens of S. pseudoglobulus (Quebec and Wisconsin/ Minnesota) had identical barcode and LSU sequences. The LSU sequences and 22 of 25 barcode sequences from the New Jersey specimens ( $S$. globulus) were identical; 3 barcode sequences had a single $\mathrm{C} / \mathrm{G}$ substitution at position 360 in the alignment shown in Figure 1.

Comparison of the barcode sequences of $S$. pseudoglobulus and $S$. globulus revealed differences in 92 of the nucleotide positions $(15.6 \%)$ over the length of the aligned region (590 nucleotides) (Fig. 1). The translated sequences differed by 13 amino acid residues $(6.5 \%)$ (Fig. 2). The single substitution observed in the 3 samples of $S$. globulus did not affect the amino acid sequence. All of the LSU sequences from $S$. pseudoglobulus were identical, as were those from S. globulus. The LSU sequences differed at 29 nucleotide positions (2.4\%) over the length of the alignment (1,208 nucleotides) (data not shown).

One hundred forty-three specimens obtained from waterfowl in the die-off on Lake Superior in 1990 had measurable eggs in the uterus. Seven specimens had eggs 96-100 $\mu \mathrm{m}$ long (S. globulus range), 102 specimens had eggs $111-125 \mu \mathrm{m}$ long (S. pseudoglobulus range), and 34 had eggs in the overlapping range 101$110 \mu \mathrm{m}$. Within the overlapping group, most clustered at the ends of the range; 10 were $\leq 102 \mu \mathrm{m}$ long and 18 were $\geq 108 \mu \mathrm{m}$, or longer.

\section{DISCUSSION}

Differences in the barcode and LSU sequences between the 2 species are consistent with differences reported in morphology (McLaughlin et al., 1993), pathology (Roscoe and Huffman 1982, 1983; Huffman and Roscoe, 1989; Gagnon, 1990; Mucha and Huffman, 1991; McLaughlin et al., 1993), egg hatching times (McKindsey and McLaughlin, 1994), and species of first intermediate host (E. virginica vs. B. tentaculata) (Huffman and Fried, 1983; Hoeve and Scott, 1988). The DNA results indicate that the lower and upper ranges in egg size reported by McLaughlin et al. (1993) are reliable diagnostic features for the separation of these species; however, the overlapping portion remains problematic.

Overall, we obtained the most consistent results with the COI primers. These were part of primer set developed specifically for the barcode region of parasitic flatworms. Virtually all of the specimens amplified successfully with them. The magnitude of the differences of the barcode sequences found between the species falls within the range of those found between other congeneric digeneans (Moszczynska et al., 2009). The LSU specimens were more difficult to sequence, likely due to deterioration of the samples. The sequences obtained were less variable than those of 
S. pseudoglobulus

S. globulus

S. pseudoglobulus

S. globulus

S. pseudoglobulus

S. globulus

S. pseudoglobulus

S. globulus

S. pseudoglobulus

S. globulus

S. pseudoglobulus

S. globulus

S. pseudoglobulus

S. globulus

S. pseudoglobulus

S. globulus

S. pseudoglobulus

S. globulus

S. pseudoglobulus

S. globulus

S. pseudoglobulus

S. globulus

S. pseudoglobulus

S. globulus
ATATATTTAATTATGGGCATTTGGGGGGGATTTTTAGGTCTTTCCTTGAG .T..A.G. . . . . . . . . . . . . . . . .A. .

TATGTTAATTCGGATGAAATTTTTAGATCCATATTATAATCTGATAAGTC ...........A.T....G...T......AT.A.... .

CTGAGGTTTATAAATTTATTATTACGAATCATGGGATTGTGATGATTTTT .G. . . . . . . G.A. . . . . . . . ........ TTCTTTTTGATGCCGGTTCTTATTGGGGGGTTCGGTAAATATTTGCTTCC

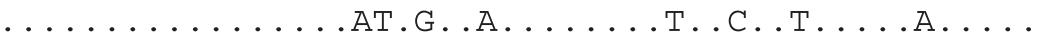
TTTATTATTGGGTCTTCCTGACCTAAACCTCCCTCGCTTAAATGCTTTGA .........T.A..G. .TT.G.TT.G...T..G...... GTGCGTGGTTGTTGTTACCCGCTGCAGTCTGTTTAGGTATTAGTATGGTG .G..T..C.C.A..G.T...T. T....G..GG.A......A GGGGGTACGGGTGTCGGTTGAACATTTTATCCTCCTCTTTCTAGCGGGGA

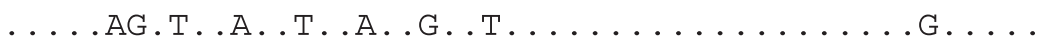

TTATTCTGGTTGAGGTGTTGATTTCTTGATGTTTTCTCTTCATTTGGCTG G......S........T.A......AT.G..C.T..A. GTATTTCTAGGATTTTTGGTTCTATAAAATTTATTTGTACTATTTTTGAA .GG................ . . . . . . . . G GTTCTTATGGAGGAGCGTAGAGAGCGTCATAGTATTTTGATTTGGGCGTA $\ldots \ldots \ldots \ldots \ldots \ldots$. . . . . . . . . . . . . T. . TCTCTTTACTTCTATTCTGTTGTTATTATCTTTGCCCGTGTTAGCGGCTG

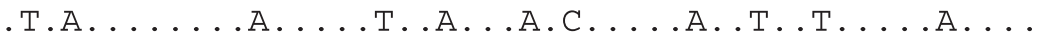

CAATTACTATGTTACTTTTTGATCGTAAATTTAGTGCTTC [590]

.Т...... T. ........... [590]
$[50]$

$[50]$

[100]

[100]

[150]

[150]

[200]

[200]

[250]

[250]

[3 000$]$

[300]

[350]

[350]

$[400]$

[4 000$]$

$[450]$

[450]

$[500]$

$[500]$

[550]

[550]

FIGURE 1. Nucleotide alignment of partial barcode sequences of Sphaeridiotrema pseudoglobulus and Sphaeridiotrema globulus.

the barcode sequences. However, the number of differences observed was comparable to those found between LSU sequences of congeneric flukes in other studies (e.g., Razo-Mendivil et al., 2004; León-Règanon et al., 2005) and support results obtained with the DNA barcode data.

Sphaeridiotrema pseudoglobulus was the only species detected in the Wisconsin/Minnesota samples; we did not detect S. globulus.
The first intermediate host of $S$. pseudoglobulus, B. tentaculata, is an invasive species that was first detected in Lake Michigan in the 1870s (see Mills et al., 1993). It now occurs widely throughout the Great Lakes Basin (Burch, 1989) and the St. Lawrence River drainage system (Clarke, 1981) and is present in the upper Mississippi River, including areas adjacent to Minnesota, Iowa, and Wisconsin (Sauer et al., 2007; Herrmann and Sorensen, 2009),
S. pseudoglobulus

S. globulus

S. pseudoglobulus

S. globulus

S. pseudoglobulus

S. globulus

S. pseudoglobulus

S. globulus
MYLIMGIWGGFLGLSLSMLIRMNFLDPYYNLMSPEVYNF I ITNHGIVMIF

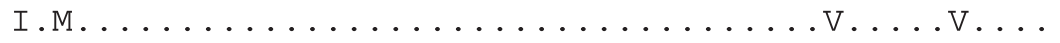

FFLMPVLIGGFGNYLLPLLLGLPDLNLPRLNALSAWLLLPAAVCLGISMV

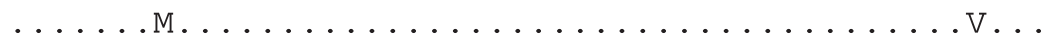

GGTGVGWTFYPPLSSGDYSGWGVDFLMFSLHLAGISSIFGSMNFICTIFE

$\ldots$ A................................ .

VLMEERSERHS ILIWAYLFTS ILLLLSLPVLAAAITMLLFDRNFSAS

$\ldots \ldots \ldots \ldots . . \ldots \ldots \ldots . \ldots \ldots \ldots$
$[50]$

[50]

[100]

[100]

[150]

[150]

[197]

[197]

Figure 2. Amino acid alignment of the translated barcode sequences of Sphaeridiotrema pseudoglobulus and Sphaeridiotrema globulus. 
and Lake Winnibigoshish, Minnesota (NWHC, unpubl. obs.). The spread of this snail has also led to the subsequent establishment of $S$. pseudoglobulus throughout these regions.

The presence of $S$. pseudoglobulus in the Wisconsin/Minnesota samples, however, is not consistent with the reports of hemorrhagic enteritis in waterfowl in the region. Sphaeridiotrema pseudoglobulus has been associated with waterfowl mortality and is a potential threat to waterfowl when present in large numbers (Hoeve and Scott, 1988), but there is no evidence from natural or experimental infections that this species causes the hemorrhagic enteritis characteristic of S. globulus infections (Hoeve and Scott, 1988; Gagnon, 1990; McLaughlin et al., 1993). However, these studies were limited to observations on surface feeding ducks. There are no experimental data regarding the effects of $S$. pseudoglobulus on diving species such as scaup, which seem to be more severely affected by the parasite. Moreover, these studies involved parasite intensities that were far less than those found in lesser scaup (see Sauer et al., 2007). Vascular leakage (as demonstrated by Evans blue injection prior to necropsy) occurs in comparatively light infections, i.e., $<90 \mathrm{~S}$. pseudoglobulus (Gagnon, 1990), and the possibility exists that massive infections like those reported by Sauer et al. (2007) could result in hemorrhage because of the extensive trauma high-intensity infections would cause to the intestinal lining.

Although we did not detect $S$. globulus in the Wisconsin and Minnesota samples, the few flukes from this sample $(N=19)$ that were sequenced represented only a small fraction of the thousands present in the Wisconsin/Minnesota birds. The possibility therefore exists that both species were present, but only 1 was detected. Evidence in support of this suggestion comes from 2 sources. First, the general pathology of infections described in coots and waterfowl in Wisconsin (Trainer and Fischer, 1963; Sauer et al., 2007 ) is consistent with current information on infections by $S$. globulus, not S. pseudoglobulus. Second, measurements of eggs from specimens obtained from lesser scaup that died on Lake Superior near Black Bay, Ontario, indicate that at least 4 of the 10 birds examined may have been infected with $S$. globulus. The acute nature of the disease suggests that the majority of birds die on, or near, the wetland where they acquired the infection; so we believe that these infections were acquired locally. Elimia virginica, the first intermediate host of $S$. globulus in New Jersey (Huffman and Fried, 1983) also occurs in the Great Lakes basin (Burch, 1989) although its distribution is not well documented. Our Ontario data indicate that $S$. globulus is present in Lake Superior and its presence in states bordering Lake Superior and Lake Michigan would not be surprising.

\section{ACKNOWLEDGMENTS}

We thank Dr. Lynn Miller, Le Nichoir, Hudson, Quebec, and Dr. David Marcogliese, St. Lawrence Centre, Environment Canada, for duck carcasses and snails, respectively, from Lake St. Louis, Quebec. We thank Dr. David Marcogliese, Environment Canada, Sean Locke, Concordia University, Dr. Gregory Sandland, University of Wisconsin-La Crosse, and Judy Williamson, USGS, NWHC for their helpful insights and comments on this manuscript. Sean Locke and Angela-Rose Lapierre, Concordia University, provided additional barcode sequences and technical assistance, respectively. We also thank Stephen Greiman, University of North Dakota, for his assistance in laboratory processing of some samples. J.D.M. and S.D. are supported by Natural Sciences and Engineering Research Council of Canada Discovery Grants A-6979 and 227575, respectively. V.T. was supported by the NSF DEB award 1021431. J.D.M. also acknowledges support through funding to the Canadian Barcode of Life Network and
Genome Canada (through the Ontario Genomic Institute), NSERC and other sponsors listed at http://www.BOLNET.ca. Use of trade or product names does not imply endorsement by the U.S. Government.

\section{LITERATURE CITED}

Burch, J .B. 1989. North American freshwater snails. Malacological Publications, Hamburg, Michigan, 369 p.

Clarke, A. H. 1981. Freshwater snails of Canada. National Museum of Natural Sciences, National Museum of Canada, Ottawa, Canada, $446 \mathrm{p}$.

Cornwell, G. W., And A. B. Cowan. 1963. Helminth populations of the canvasback (Aythya valisineria) and host-parasite-environmental interrelationships. In Transactions of the Twenty-Eighth North American Wildlife and Natural Resources Conference, James B. Trefethen (ed.). Wildlife Management Institute, Washington, D.C., p. 173-199.

Cywinska, A., F. F. Hunter, and P. D. N. Hebert. 2006. Identifying Canadian mosquito species through DNA barcodes. Medical and Veterinary Entomology 20: 413-424.

Gagnon, C. 1990. Pathological consequences of infection by Cyathocotyle bushiensis Khan, 1962 and Sphaeridiotrema globulus (Rudolphi, 1814) in two species of dabbling ducks. M.S. Thesis. McGill University, Montreal, Quebec, Canada, 167 p.

Gower, W. C. 1938. Studies on the trematode parasites of ducks in Michigan with special reference to the mallard. Memoirs of the Michigan State College Agricultural Experimental Station 3, East Lansing, Michigan, 94 p.

Hajibabaei, M., D. H. Janzen, J. M. W. Hallwachs, and P. D. N. Hebert. 2006. DNA barcodes distinguish species of tropical Lepidoptera. Proceedings of the National Academy of Sciences USA 103: 968-971.

Hebert, P. D. N., A. Cywinska, S. L. Ball, and J. D. de Waard. 2003. Biological identifications through DNA barcodes. Proceedings of the Royal Society B: Biological Sciences 270: 313-321.

Herrmann, K., and R. E. Sorensen. 2009. Seasonal dynamics of two mortality-related trematodes using an introduced snail. Journal of Parasitology 95: 823-828.

Hoeve, J., And M. E. Scott. 1988. Ecological studies on Cyathocotyle bushiensis (Digenea) and Sphaeridiotrema globulus (Digenea), possible pathogens of dabbling ducks in Quebec. Journal of Wildlife Diseases 24: $407-421$.

Huffman, J. E. 2008. Trematodes. In Parasitic diseases of wild birds, C.T. Atkinson, N. J. Thomas, and D. B. Turner (eds.). Wiley-Blackwell, Ames, Iowa, p. 225-245.

, AND B. FRIED. 1983. Trematodes from Goniobasis virginica (Gastropoda: Pleuroceridae). Journal of Parasitology 69: 429.

- AND D. E. Roscoe. 1989. Experimental infections of waterfowl with Sphaeridiotrema globulus. Journal of Wildlife Diseases 25: $143-146$.

León-Règagnon, V., S. Guillén-Hernández, And M. A. ArizmendiEsPINOSA. 2005. Intraspecific variation of Haematoloechus floedae Harwood, 1932 (Digenea: Plagiorchiidae), from Rana spp. in North and Central America. Journal of Parasitology 91: 915-921.

Locke, S. A., J. D. Mclaughlin, S. Dayanandan, And D. J. Marcogliese. 2010. Diversity and specificity in Diplostomum spp. metacercariae in freshwater fishes as revealed by DNA barcodes and ITS sequences. International Journal for Parasitology 40: 333-343.

- - A. R. Lapierre, P. T. J. Johnson, And D. J Marcogliese. 2011. Linking larvae and adults of Apharyngostrigea cornu, Hysteromorpha triloba and Alaria mustelae (Diplostomoidea: Digenea) using molecular data. Journal of Parasitology 97: 846-851. - - AND D. J. MArcogliese. 2010. DNA barcodes show cryptic diversity and a potential physiological basis for host specificity in the Diplostomoidea (Platyhelminthes: Digenea) parasitizing freshwater fishes of the St. Lawrence River, Canada. Molecular Ecology 19: 2813-2827.

McKindsey, C. W., And J .D. McLaughlin. 1994. Hatching dynamics of eggs as further evidence for the existence of two separate species of Sphaeridiotrema (Digenea) in eastern North America. Journal of the Helminthological Society of Washington 6: 126-127.

Mclaughlin, J. D., M. E. Scott, and J. E. Huffman. 1993. Sphaeridiotrema globulus (Rudolphi, 1814) (Digenea): Evidence for 
two species known under a single name and a description of Sphaeridiotrema pseudoglobulus n. sp. Canadian Journal of Zoology 71: 700-707.

Mills, E. L., J. H. Leach, J. T. Carleton, and C. L. Seacour. 1993. Exotic species in the Great Lakes: A history of biotic crises and anthropogenic introductions. Journal of Great Lakes Research 19: $1-54$.

Moszczynska, A., S. A. Locke, J. D. McLaughlin, D. J. Marcogliese, AND T. J. CREASE. 2009. Development of primers for the mitochondrial cytochrome c oxidase gene in digenetic trematodes (Platyhelminthes) illustrates the challenge of barcoding parasitic helminths. Molecular Ecology Resources 9(Suppl. 1): 75-82.

Mucha, K. H., AND J. E. HuffMan. 1991. Inflammatory cell stimulation and wound healing in Sphaeridiotrema globulus experimentally infected mallard ducks. Journal of Wildlife Diseases 27: 428-433.

Nolan, M. J., AND T. H. CRibB. 2005. The use and implications of ribosomal DNA sequencing for the discrimination of digenean species. Advances in Parasitology 60: 101-163.

Olson, P. D., AND V. V. TKaCh. 2005. Advances and trends in the molecular systematics of the parasitic Platyhelminthes. Advances in Parasitology 60: 171-243.

Price, E. W. 1934. Losses among wild ducks due to infestation with Sphaeridiotrema globulus (Rudolphi) (Trematoda; Psilostomidae). Proceedings of the Helminthological Society of Washington 1: 31-34.
Razo-Mendivil, U. J., V. León-Règagnon, and Gerardo Pérez-Ponce DE LEÓN. 2004. Description of two new species of Glypthelmins Stafford, 1905 (Digenea: Macroderiodidae) in Rana spp. from Mexico, based on morphology and mtDNA and rDNA sequences. Systematic Parasitology 59: 199-210.

Roscoe, D. E., and J. E. Huffman. 1982.Trematode (Sphaeridiotrema globulus) induced ulcerative hemorrhagic enteritis in wild Mute Swans (Cygnus olor). Avian Diseases 36: 214-224.

, AND . 1983. Fatal enteritis caused by Sphaeridiotrema globulus (Trematoda: Psilostomatidae) in a whistling swan. Journal of Wildlife Diseases 19: $370-371$.

Sauer, J. S., R. A. Cole, And J. M. Nissen. 2007. Finding the exotic faucet snail (Bithynia tentacualta): Investigation of waterbird die-offs in the Upper Mississippi River National Wildlife and Fish Refuge. U.S Geological Survey Open-File Report 2007-1063, Reston, Virginia, 3 p.

Speckmann, G. A., A. Robertson, and W. A. Webster. 1972. Sphaeridiotrema flukes, the cause of ulcerative enteritis in a cygnet (Cygnus olor). Journal of Wildlife Diseases 8: 1-2.

TKach, V. V., D. T. J. Littlewood, P. D. Olson, J. M. Kinsella, and Z. SwidersKi. 2003. Molecular phylogenetic analysis of the Microphalloidea Ward, 1901 (Trematoda: Digenea). Systematic Parasitology 56: $1-15$.

Trainer, D. O., and G. W. Fischer. 1963. Fatal trematodiasis in coots. Journal of Wildlife Management 27: 483-486. 